\title{
ANALYSIS OF ELECTRIC FIELD ON THE CIRCULAR COLLECTOR
}

\author{
Josef SKRIVANEK, Ondrej BATKA, Jan VALTERA \\ TUL - Technical University of Liberec, Department of Textile Machine Design, Liberec, Czech Republic, EU, \\ josef.skrivanek@tul.cz
}

https://doi.org/10.37904/nanocon.2019.8671

\begin{abstract}
The paper deals with simulations of the distribution of electric field on the collector surface during the DCelectrospinning process. The object of the simulations was to find out whether it is possible to achieve a uniform distribution of the electric field on the surface of the circular collector. The homogenity of the nanofiber layer formed on the collector is related to the uniformity of the distribution of the electric field. Simulations were performed for different shapes of the circular collector, where the geometry of the collector edge was changed. From the simulation results it was found that a suitable adjustment of the collector edge geometry has a significant effect on the distribution of the electric field on the collector surface.
\end{abstract}

Keywords: Colector, electrospinning, electric field, high voltage

\section{INTRODUCTION}

At present electrically charged collectors coated with non-woven fabric are used to capture nanofibers produced by the electrospinnig method. [1] This research deals with the issue of circular collectors, which are used for the production of small laboratory samples also of circular shape. Due to the unevenness of the electric field on the collector surface, more nanofibres move from the electrode to the edges of the collector than to its center. For this reason, the layer of produced fibers on the non-woven fabric is uneven, especially at the edges the unevenness increases greatly. This occurrence is caused by the high value of the electric field at the collector edges. Especially if the collector edge is terminated by a sharp edge, the intensity values are extremely high. [2] [3] At present, this negative effect is compensated by the use of a collector with a diameter larger than the required sample size, which entails requirements for a larger installation space, which is otherwise completely unused and thus increases the dimensions of the entire device. The aim of this work is to design a new shape of the collector and to analyze the distribution of the electric field on the collector surface in relation to the made modifications. The result should be to design a shape that would make the electric field distribution more uniform on its surface and reduce the intensity values at the collector edges. Using such a designed collector it would be possible to produce a more uniform layer of fibers of greater width while maintaining the overall diameter, including the installation dimensions.

\section{SIMULATIONS}

\subsection{FEM model}

In Figure 1 (a) a simplified diagram of the device is shown with the basic parts needed for the simulation, namely the electrode, the collector and the machine frame. Simulations were performed using the finite element method, using Autodesk Simulation Mechanical software. Since both the collector and the electrode are rotationally symmetrical bodies, the task was simulated as rotationally symmetrical. In Figure $\mathbf{1}$ (b) the general computational model used in simulations is shown. The individual dimensions shown in Figure 1 (a), including the electrode dimensions, did not change to the diameter $D$ or the collector shape itself during the 
simulations. The shape of the collector was modified in individual steps of the performed analysis and the distribution of the electric field on the collector was always evaluated from the performed electrostatic field simulation. Changes made to the shape are described in the next section. The polymer was also simulated onto the electrode surface, from which fibers are formed in a real production. The shape was simplified to a hemispherical drop and was retained in all simulations performed. The boundary conditions were given the electric voltages on the individual parts. A positive voltage of $20 \mathrm{kV}$ was applied to the lower edge of the electrode. Negative voltage $-20 \mathrm{kV}$ per collector. The frame of the device is grounded, so a voltage of $0 \mathrm{~V}$ has been entered. These values of boundary conditions entered in this way were also not changed during the simulations performed.

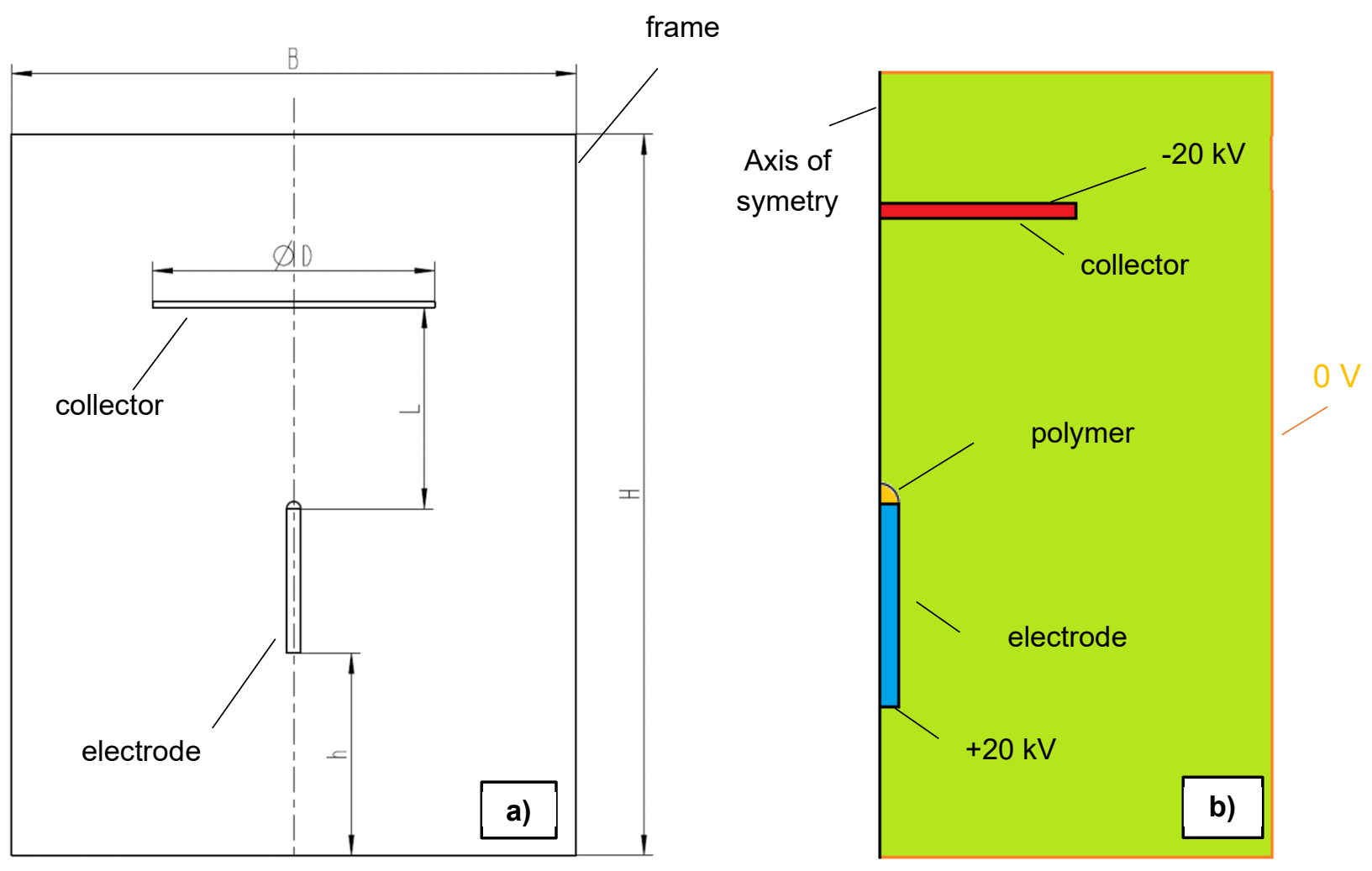

Figure 1 FEM model

\subsection{Simulation of standard shape collector}

First, the basic shape of the collector was analysed, Basic collector is a circular plate with rounded edges at the edges corresponding to the thickness of the sheet which it is made of. Specifically, it is $2 \mathrm{~mm}$ and the collector diameter is $200 \mathrm{~mm}$. Figure 2 shows the distribution of the electric field intensity around. There are shown values of electric field for specific points, specifically for the centre of the collector, the half distance of the collector radius and for the edge of collector. It is evident that there is a high intensity at the edge. The value at the edge $(2140 \mathrm{~V} / \mathrm{mm})$ is, more than ten times than the value in the middle of the collector $(180 \mathrm{~V} / \mathrm{mm})$. The graph in Figure 3 shows the electric field distribution on the collector surface from its middle to the edge. It can be seen from the graph in Figure 3 that there is a significant increase in the electric field intensity at the collector edge, which leads to an increase the unevenness of the nanofiber layer as described in the introduction. 


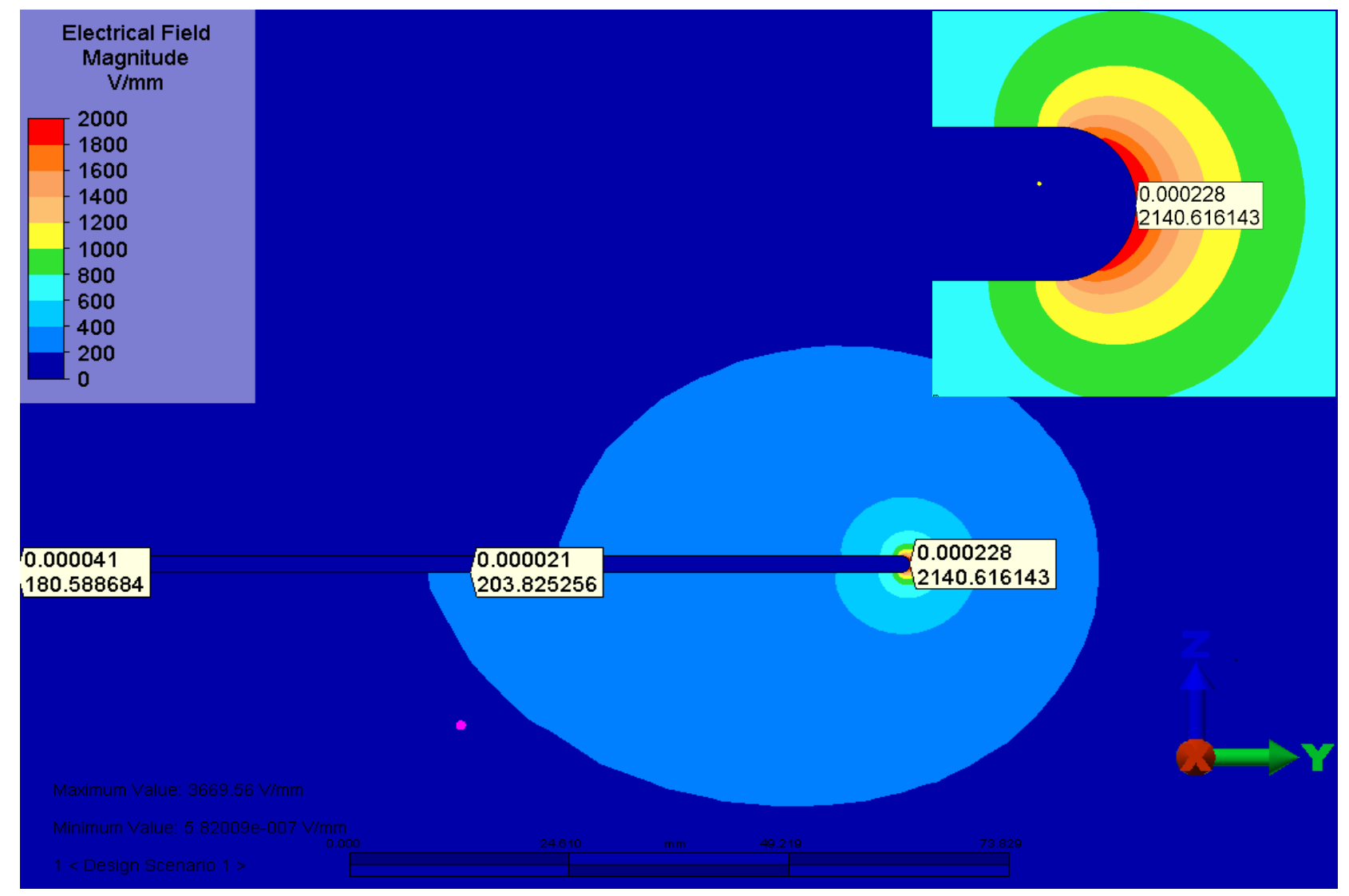

Figure 2 Simulation for basic collector

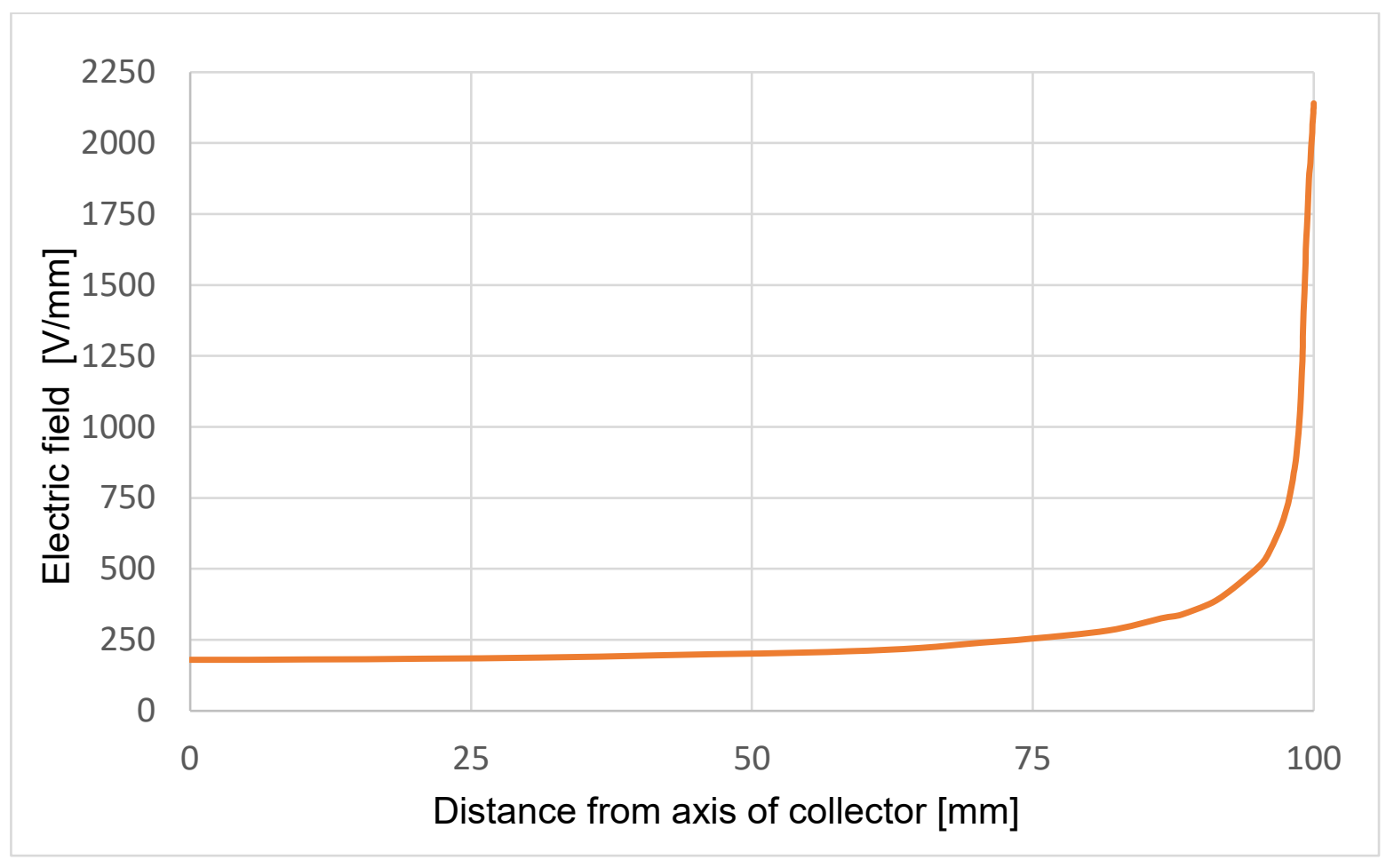

Figure 3 Electric field distribution on surface of basic collector 


\subsection{Simulation of new designed shape of collector}

The design of the new collector shape is based on the assumption that the use of a larger diameter radius will reduce the intensity value at the collector edge. The collector was modeled again as a circular plate supplemented with a torus-shaped body on the edge, Figure 4. The total diameter of the collector, including the end, is chosen in the same way as the basic shape from the previous chapter, ie 200 millimeters. The ending diameters ( $\phi \mathrm{d}$, Figure 4 ) were varied and their effect on intensity distribution was analyzed. Specifically, two values were chosen, namely a diameter of 20 millimeters and a diameter of 50 millimeters.

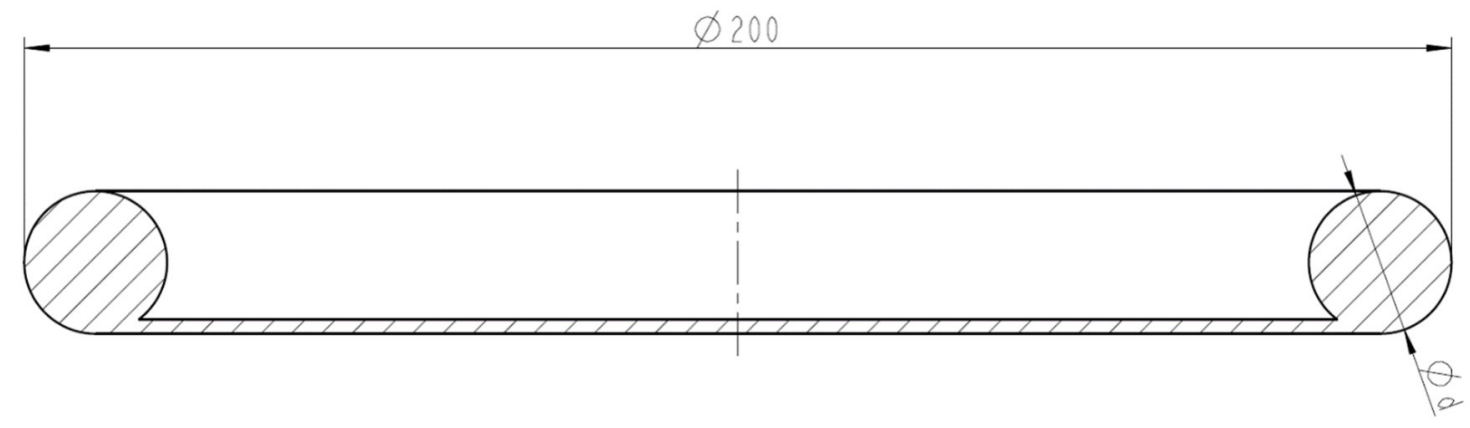

Figure 4 New shape of collector

In Figure 5, the distribution of the electric field intensity around the collector is shown with an edge having a diameter of $20 \mathrm{~mm}$. It can be seen from the figure that there is a significantly lower intensity value at the collector edge than in the basic shape from the previous simulation. Figure 6 shows an electric field distribution around a collector with a rounded edge of $50 \mathrm{~mm}$ diameter. It can be seen that the electric field value at the collector edge is lower than the $20 \mathrm{~mm}$ diameter variant. Figure 7 shows a comparison of the electric field distribution on the surface of all analyzed collector shapes.

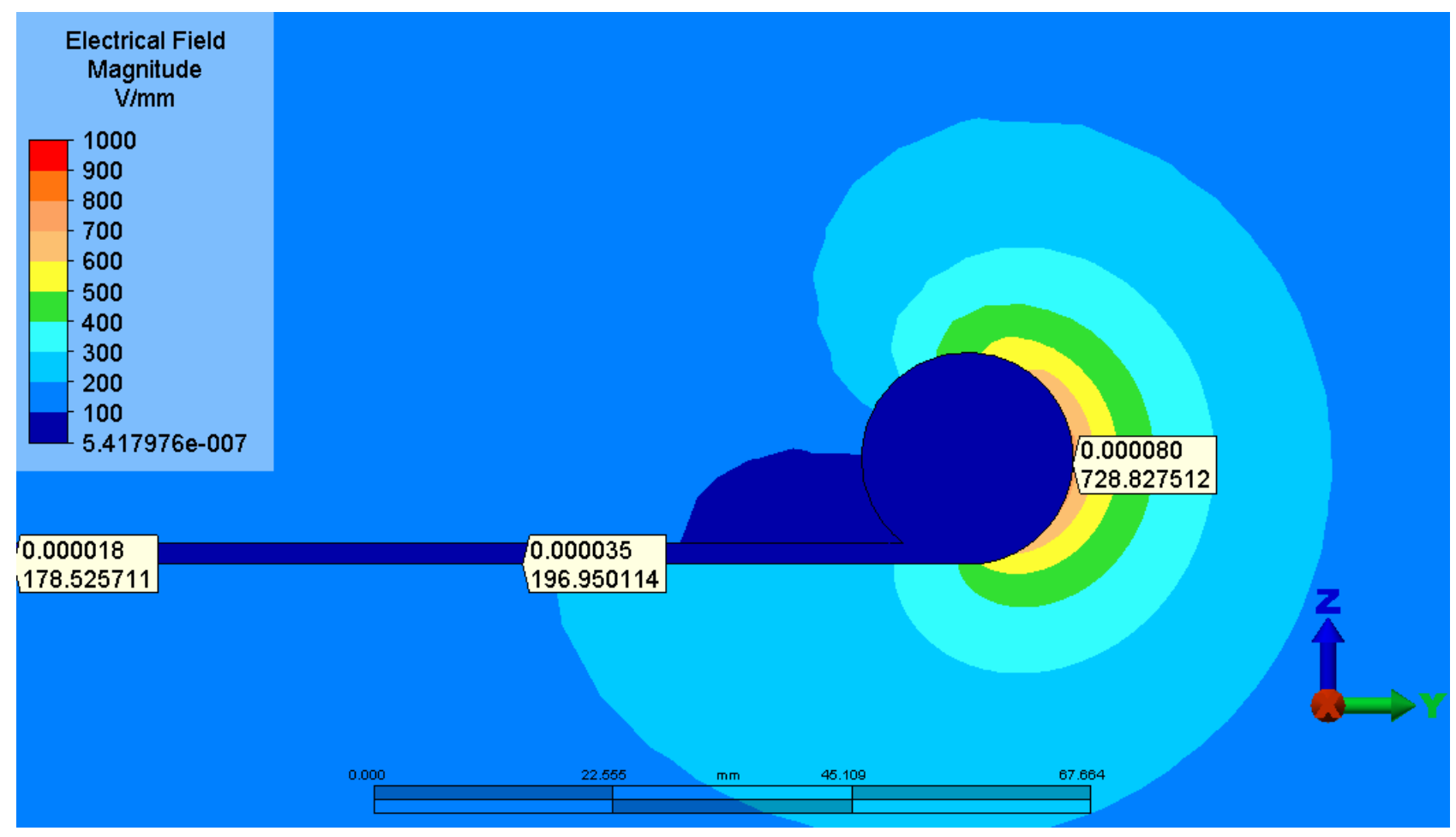

Figure 5 Electric field distribution around collector for rounded edge value $20 \mathrm{~mm}$ 


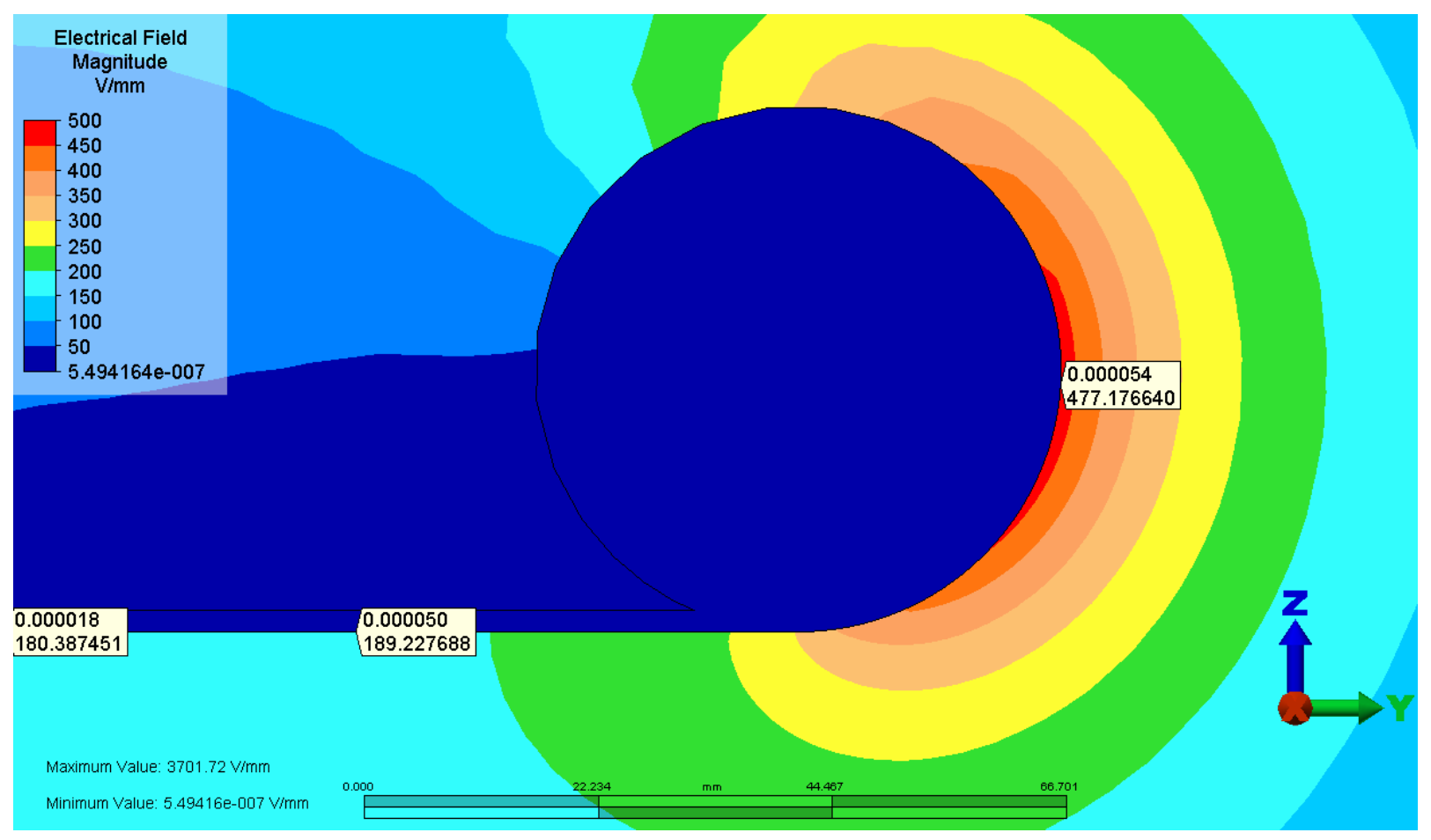

Figure 6 Electric field distribution around collector for rounded edge value $50 \mathrm{~mm}$

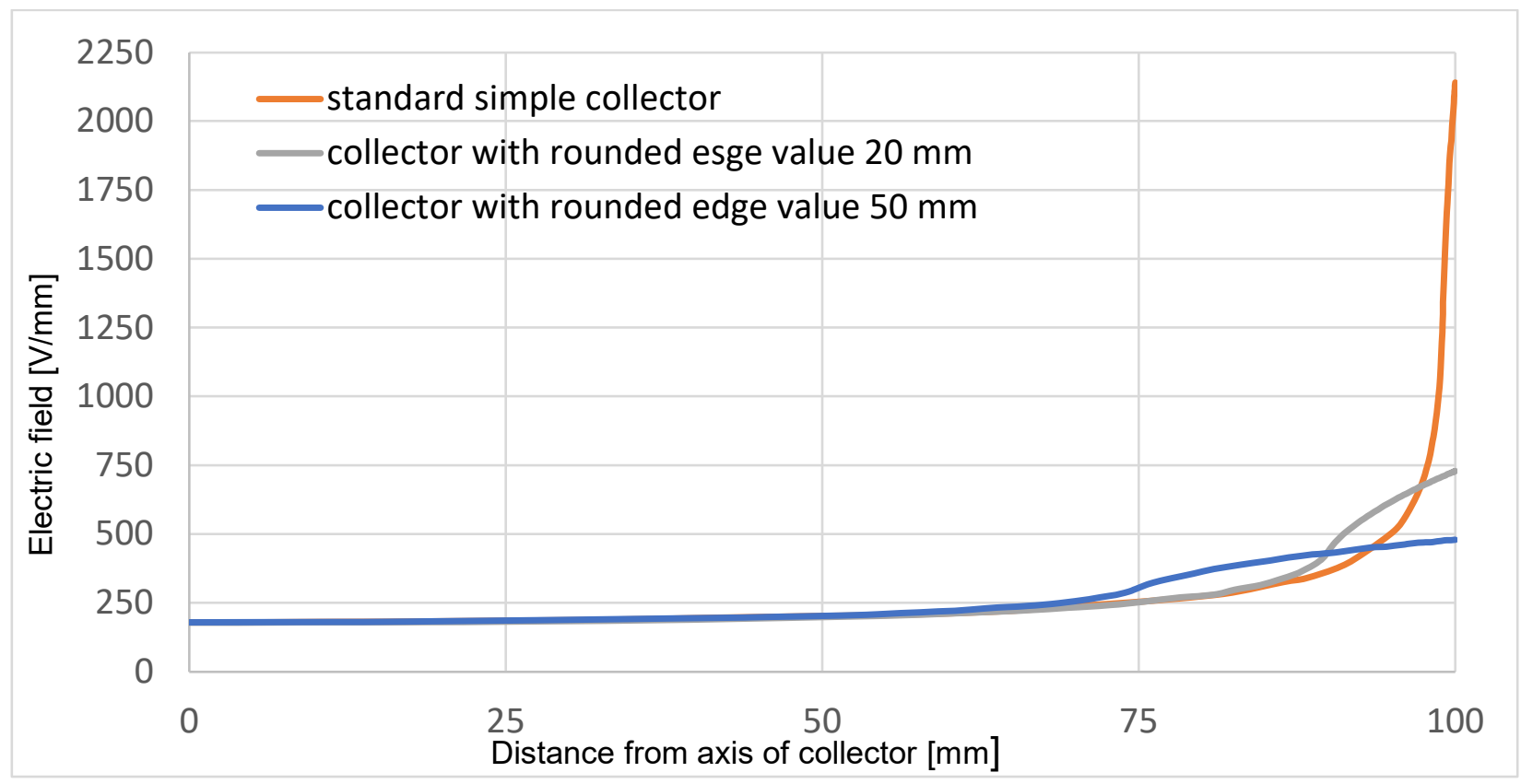

Figure 7 Comparation electric field distribution on surface of three types of collectors

\section{CONCLUSION}

The carried out simulations show that the electric field values at the collector edge with rounding are of the order of magnitude lower than for the basic collector. The distribution of the electric field intensity is more uniform for rounded collectors than for the basic collector. An important benefit of applying larger rounding diameters is in particular the reduction of the electric field at the collector edge. The consequence of this should 
be to increase the uniformity of the nanofiber layer applied to the base fabric, while maintaining the same value of the collector diameter. If the new shape of the collector is used, the requirement for installation dimensions will be reduced, and thus the whole device can be smaller.

\section{ACKNOWLEDGEMENTS}

This publication was written at the Technical University of Liberec as part of the project 21287 with the support of the Specific University Research Grant, as provided by the Ministry of Education, Youth and Sports of the Czech Republic in the year 2019.

\section{REFERENCES}

[1] JIRSAK O., SANETRNIK F., LUKAS D., KOTEK V., MARTINOVA L., and CHALOUPEK J., "A method of nanofibres production from a polymer solution using electrostatic spinning and a device for carrying out the method," WO 2005/024101 A1, 2005.

[2] POKORNY P., K. E. (2014). Effective AC needleless and colector less electrospinning for yarn production. Physical Chemistry Chemical Physics, 16 (48), pp. 26816-26822.

[3] ZELENY, J. The electrical discharge from liquid points, and a hydrostatic method of measuring the electric intensity at their surfaces. Physical Review, 3(2), 69-91. https://doi.org/10.1103/PhysRev.3.69.

[4] TAYLOR G. Electrically driven jets (1969) Proceedings of the Royal Society of London, Series A, Mathematical and Physical Sciences, 313 (1515), pp. 453-475.

[5] JIRSAK, O., SYSEL, P., SANETRNIK, F., HRUZA, J., \& CHALOUPEK, J. (2010). Polyamic acid nanofibers produced by needleless electrospinning. Journal of Nanomaterials, 2010. https://doi.org/10.1155/2010/842831.

[6] VALTERA, J., KALOUS, T., POKORNY, P., BATKA, O., BILEK, M., CHVOJKA, J., LUKAS, D. (2019). Fabrication of dual- functional composite yarns with a nanofibrous envelope using high throughput $A C$ needleless and collectorless electrospinning. Scientific Reports, 9(1). https://doi.org/10.1038/s41598-019-38557-z.

[7] SKRIVANEK J., BATKA O., BILEK M., VALTERA J., LE VAN K., Effect analysis of the string cross-section on the electrostatic spinning proces. (2017) NANOCON 2017 - Conference Proceedings, 9th International Conference on Nanomaterials - Research and ApplicationVolume 2017-October, 2018, Pages 224-228.

[8] RŮŽıČKOVÁ, J. Electrostatic spinning of nano fibres, ISBN 80-7372-066-3, Liberec: Technical University of Liberec, 2006, p 11. 